\title{
Literatur.
}

1) A be, T., Dieses Journ., 1947, 49, 27.

2) I ma iz um i; M., Journ. Biochem., 1938, 27, 199.

3) Sait oo, H., ibidem, 1941, 34, 49, 103 u. 223.

4) Onisi, T., ibidem, 1941, 34, 325.

5) Osima, K., Jap. Journ. Med. Science. Biochem., 1944, 5, 101, 115, 123 u. 141.

6) Quastel, J. M. u. Woolf. B., Biochem. Journ., 1926, 20, 545.

7) Cook, R. P. us Woof, B., ibidem, 1938, 22, 474.

\section{Our Blood Picture-ELMON-ogram; Simple Blood Picture demonstrating even to Layman whether Normal or Abnormal. Preliminary Report.}

By

Akira Sato and Katsumi Hayashi.

(佐 藤 彰) (林 克已)

(From Department of Pediatrics, Faculty of Medicine, Tohoku University, Sendai. Director: Prof. A. S a to).

(Received for publication, July 5, 1946)
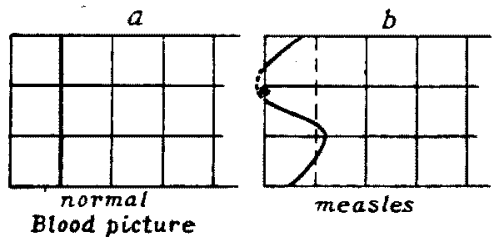

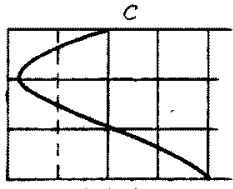

scarlet fever

Fig.l

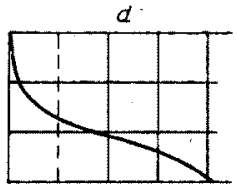

appendicitis

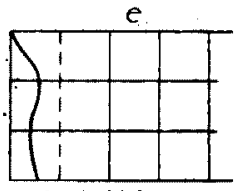

typhoid fever

The line or curve shown above will at once demonstrate the convenience of ELMoN-ogram, our blood picture. How could the normal line be a straight one, while the normal counts e.g. of eosinophiles and neutrophiles are very different? The following figures (Fig. 3) will show the reason :-

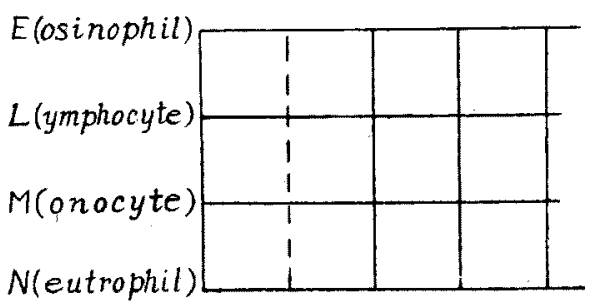

Fig.2

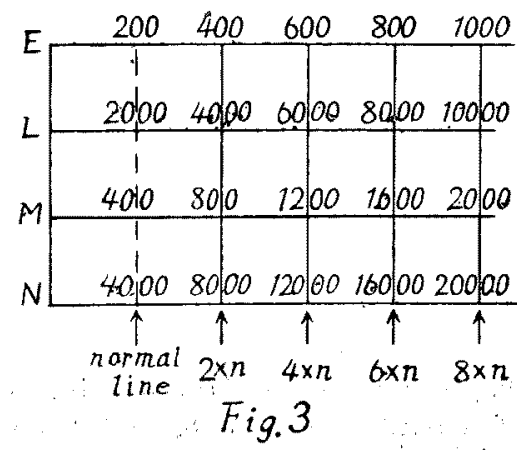


We do not use the percentage, because this will not show the real relation; 200 eosinophiles is a normal count, while this one and the same number may become $0.5 \%$ (eosinopenia) or $20 \%$ (eosinophilia) according to a variation of total white count. This is nonsense. So we use always absolute count.

The question may rise : How about the ELMoN-ogram in children and infants, whose normal count is very different according to the age? But one and the same ELMoN-ogram is used. The following (Fig. 4) will show how it will be constructed in infancy and childhood.
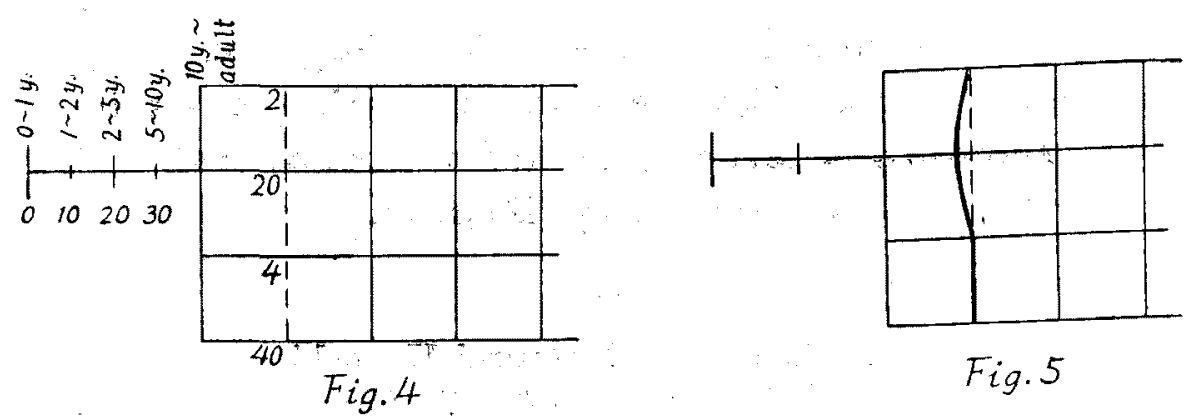

The strictly normal line for all ages will be like Fig. 5 . But one will see that it will not matter much, even if we draw a straight line. The details of the present treatise will be reported in a forthcoming hematological paper (cf. Tohoku J. Exp. Med).

Paper read at the 11th Meeting of the Society of Research of Diseases Gaused by Acid-fast Bacilli held Dec. 8, 1944, Sendai. 